\title{
Virtual Enterprise Environments (VEEs) to Enable Innovation in Collaborative Networks - Initial Modelling Approach
}

\author{
Benjamin Knoke and Jens Eschenbächer \\ BIBA - Bremer Institut für Produktion und Logistik GmbH, \\ Hochschulring 2028359 Bremen, Germany \\ $\{k n o, e s c\} @ b i b a . u n i-b r e m e n . d e$
}

\begin{abstract}
This paper describes the terminology of Virtual Enterprise Environments as a construct to enable the combination of spaces for open innovation and Virtual Enterprises. This shall contribute towards better management of innovation processes in collaborative networks. Consequently this includes the Business Innovation Space and the Value Production Space, which are shared by the collaborating enterprises. Initial attempts are made to characterize the schematics of these spaces and their interactions.
\end{abstract}

Keywords: Virtual Enterprise Environment, Open Innovation, Innovation Space, Value Production Space, modelling innovation processes.

\section{Introduction}

While Business Innovation itself is a widely used and unclear term [1], only few accepted models, approaches and tools have been developed [2]. Innovation in Collaborative Networks has been discussed in publications, such as [3], [4], [1] or [5]. However, yet there is no research work that focuses specifically on Virtual Enterprise Environments. BIVEE

Virtual Enterprise Environments (VEEs) are a term that was proposed by the BIVEE $^{1}$ project (Business Innovation in a Virtual Enterprise Environment). VEEs can be seen as new approach to tackle innovation processes in collaborative networks. It also contains the concept of open spaces like the Value Production Space and the Business Innovation Space, which allow the integration of external resources into the collaborative network.

Companies with direct end-user connection need to be one step ahead regarding the developments of new products, due to the shortening of product life cycles. Therefore being innovative has become one of the main objectives for most of these enterprises. A prominent example of this dilemma can be found within the mobile phone market, as its market dynamics change and product life cycles shrink rapidly [6]. Until the middle of the last decade, it was commonly believed that the key competence of a

\footnotetext{
${ }^{1}$ http: / /www.bivee.eu
} 
mobile phone manufacturer is to integrate standardized components into a dominant design [7], [8], [9].

Conceptualising the business processes taking place in product development (area of the Business Innovation Space) and production (Value Production Space) is a interesting challenge. The modelling of business process in VO has been discussed in many publications (e.g. Camarinha-Matos [10]). What is missing so far is a strong focus on innovation processes. This forces the question of how this concept of open innovation can be successfully implemented and modelled within a value chain or a collaborative network. A possible approach can be identified with the concept of the Virtual Enterprise Environment, which will be explained within this paper.

\section{Terminology and Characteristics towards Innovation in Virtual Enterprise Environments}

\subsection{Leading Practical Example}

A practical example illustrates the dilemma of manufacturing companies, when improving business processes in contrast to invest in new products and services. The example will draw attention to strategy options with focus on innovation, while at the same time optimising factories is very difficult. Therefore most OEMs (e.g. SonyEricsson, Motorola) have focused on process improvement and low cost production. This belief has become obsolete when Apple released the iPhone in 2007. Its multitouchscreen can be characterized as a radical innovation that revolutionized the smart phone market [11]. This new and fast-growing market has significantly decreased the revenue of high and medium quality mobile phones, as smartphones gained higher market share [12].

Table 1. Global Smartphone Vendor Marketshare \% [13], [14]

\begin{tabular}{lllll}
\hline & 2008 & 2009 & 2010 & 2011 \\
\hline Nokia & $40,00 \%$ & $38,80 \%$ & $33,40 \%$ & $15,80 \%$ \\
Apple & $9,10 \%$ & $14,40 \%$ & $15,90 \%$ & $19,00 \%$ \\
Others & $50,90 \%$ & $46,80 \%$ & $50,70 \%$ & $65,10 \%$ \\
Market Growth & $23,1 \%$ & $15,6 \%$ & $71,4 \%$ & $63,1 \%$ \\
\hline
\end{tabular}

The development of the global Smartphone vendor market share (Table 1) begs the question: What ia the reason for Nokia's decrease and Apple's success? This can be explained through the iPhone not only representing a product innovation (with its touchscreen and the possibility to display the World Wide Web and not a mobile version in 2007), but a service innovation as well, due to the combination with the Appstore [15]. This combination of the iPhone and the Appstore can be described as an intangible product and shows Apple's innovative advance. Unlike Nokia, Apple did not focus on a maximum efficient manufacturing of a broad array of products, but 
instead on a single innovative high class product. The development of the iPhone and its apps takes place within an environment, which includes contributing users. With this approach the Appstore developed far more apps, than Apple could have created on its own. The Apple App Store is a prominent example for the successful integration of an external technology base into a company's innovation process.

This business model represents a form of open innovation, which has been described by Chesborough [16]. It can be characterized as a viable option to expand innovative potential and to speed up the innovation processes [17], [18].

The topic of innovation in virtual organisations and the BIVEE project have created a few terms in the area of Virtual Enterprise Environments, which will be described within this chapter.

\subsection{Virtual Enterprise Environments}

The idea of networking is based on the collaboration of independent enterprises aiming at taking different advantages, while maintaining their individual independency [19]. The rising challenges for concurring enterprises to maintain their ability to compete have led towards a broad field of research concerning collaborations and a significant amount of terms to describe the structure of a collaborative network.

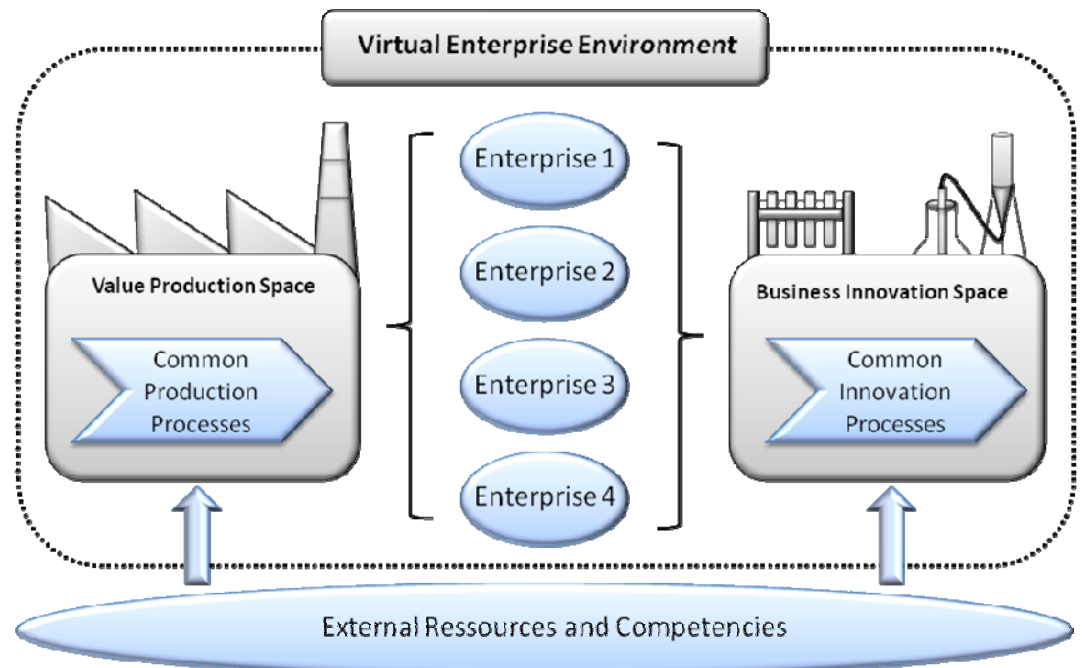

Fig. 1. Basic Structure of a Virtual Enterprise Environment

The term Virtual Enterprise Environments (VEEs) has been selected for the use within innovation networks, because it combines the inter-organisational structure of virtual enterprises with the concept of spaces, as sketched in Fig. 1. These spaces exist in the environment of a virtual enterprise. Regarding the improvement and 
innovation processes, two key spaces can be identified: The Value Production Space (VPS) and the Business Innovation Space (BIS), which will be described below.

\subsubsection{Value Production Space (VPS)}

A Value Production Space (VPS) can be described as an open system, which elements can be internal or external production units that share connections with each other. It is a real existing space in an production factory or similar, which contains the value production of the VEE. Therefore it contains added competencies and resources, which can be described as production units of the collaborating enterprises or external elements. Its openness carries the need of securing and protecting members, production units and innovations created within the VPS.

\subsubsection{Business Innovation Space (BIS)}

Compared to the VPS, the Business Innovation Space (BIS) contains highly diversified elements and processes. Instead of processing raw materials into products or elementary services into complex services, the BIS targets to create new processes and organizations based on their predecessors. Through this approach, another difference appears regarding the development of innovations. The added competencies and resources of the collaborating enterprises and external elements within the BIS can be described as creative units.

While the structured use of methods, principles and tools may support the innovation process, creativity, intuition and 'lateral thinking' are not to be put into repetitive tasks. Instead, these innovation processes can be supported by environments that allow a high level of creativity, by avoiding pressure of time and providing a comfortable and innovative environment. Especially within the IT-branch, this issue gains a significant value to successful enterprises.

\section{Discussion on the Modelling of the Virtual Enterprise Environment Spaces}

This chapter seeks to discuss the modelling of the Virtual Enterprise Environment spaces. Since these spaces are not independent, but tightly interwoven, initial attempts to map their connections are made.

\subsection{Mapping the Value Production Space (VPS)}

The processes within a VPS follow a predetermined path with defined production links and production units. These production units (modelled as circle-shaped nodes, Fig. 2) can be small- or medium-sized enterprises or parts of a single, large enterprise. Production units are connected with production links. Fig. 2 represents a drafted version of a production map. These production maps consist of the previously described production units and links as well as other elements, which represent 
additional infrastructure e.g. storage warehouses. Their purpose is to picture the flow of goods, services, financials and information, as well as providing an easy comprehension to people, not directly involved in the process.

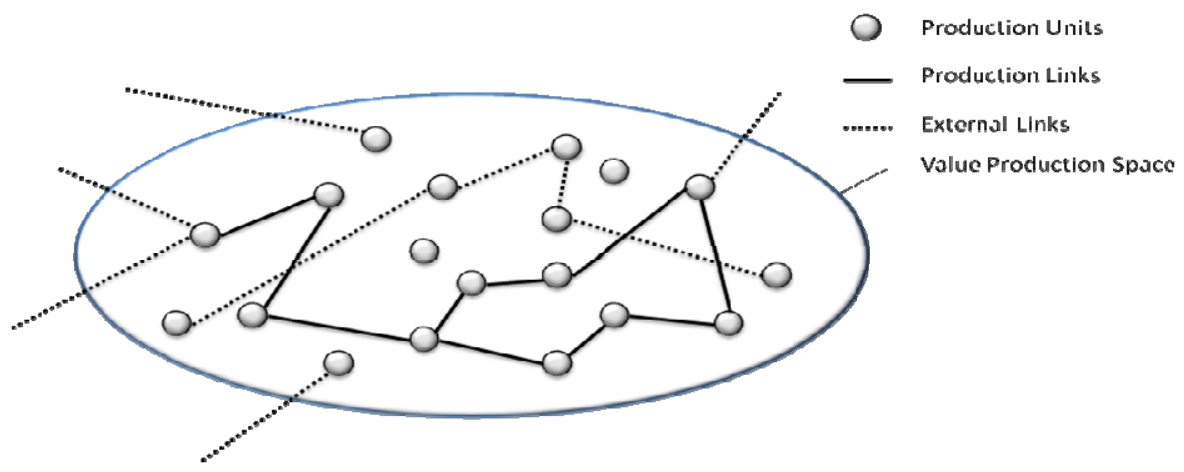

Fig. 2. First Drafted Production Map to Visualize the Value Production Space

\subsection{Mapping the Business Innovation Space (BIS)}

As well as the VPS, the BIS can also be visualised with connection and nodes. The nodes represent creative units, which are connected through cooperative interactions. These cooperative interactions are enabled by communication links and comprise the exchange of ideas and their supportive information. Using these elements, an innovation map can be made, as drafted in Fig. 3. It aims to provide an overview on the flow of knowledge, which may be created within the production process, emerges by passing through different creative units and finally leads into innovative solutions.

Radical innovations may lead into the replacement of existing elements, according to destructive innovation, as described by Schumpeter [20]. Additionally, the possibility of failure has to be taken into account, when dealing with innovation processes. Concerning this issue, it is the task of forecasting methods to determine the chances of the innovation process. This can imply the need of testing as many innovative solutions as possible; in order to achieve an optimal result.

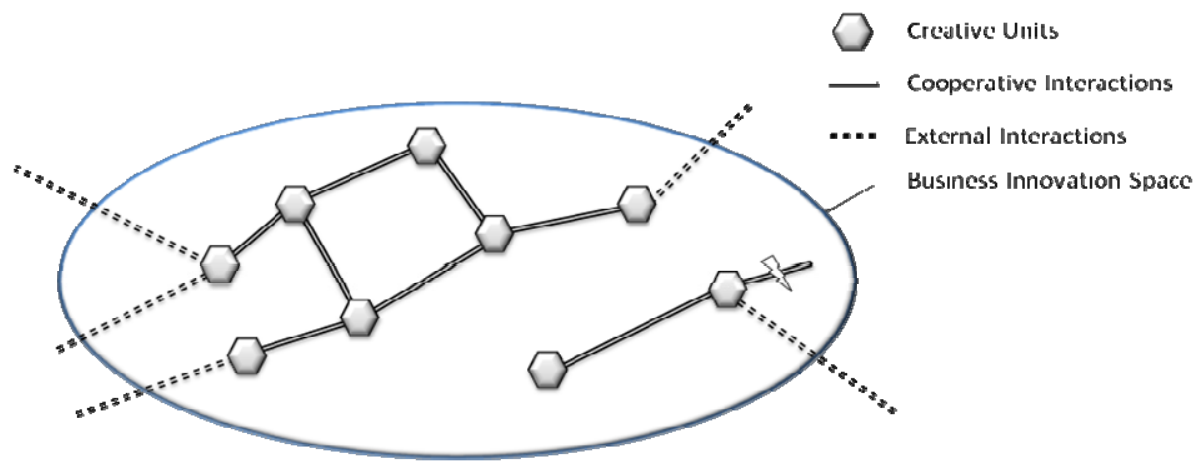

Fig. 3. First drafted Innovation Map to Visualize the Business Innovation Space (BIS) 


\subsection{Discussion towards an Integrated Model of BIS and VIS}

Following the idea of a strong connection between BIS and VPS, the mapping of these spaces and their connections into a single innovative production map is one of the key problems in the BIVEE project. The integration of the value production map and the innovation map into a combined overview becomes a challenging task regarding the differing characteristics, roles and objectives of these tightly interwoven areas. The basic approach to complete this task is to use the value production map (including the supporting organization) as substructure and to add the innovation process report to build an innovative production map, forming an integrated meta-space.

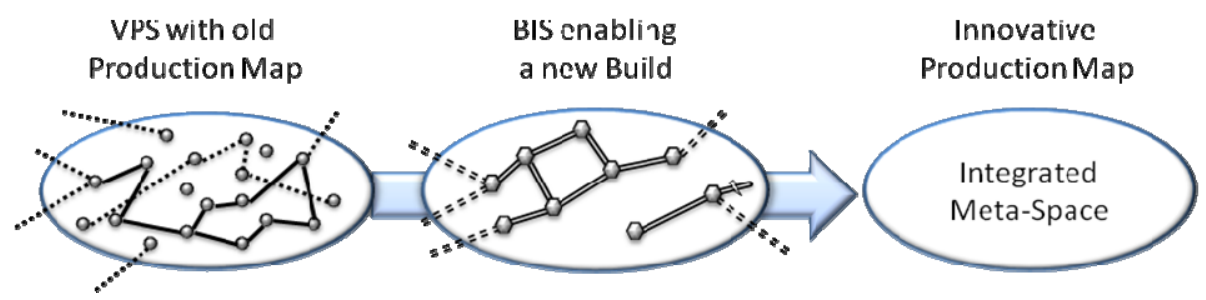

Fig. 4. Towards the Integrated Meta-Space

This process of creating such an integrated view is drafted in Fig. 4. The creation of an Innovative Production Map, framing an integrated meta-space, requires a high level of communication within the collaborating network. To cope with this challenge, the most innovative knowledge representation methods and notations need to be applied.

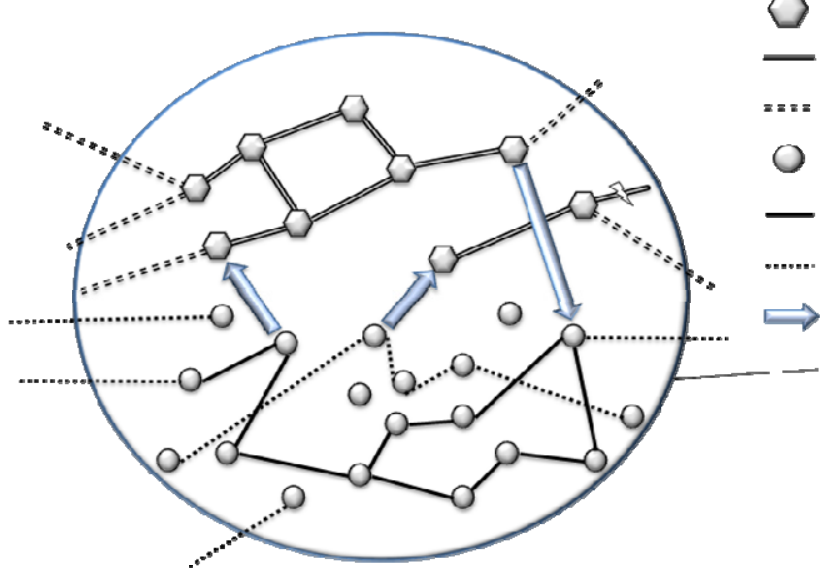

Creative Units

Cooperative Interactions

External Interactions

Production Units

Production Links

External Links

Flow of Ideas or Innovations

Integrated Mela-Space

Fig. 5. Schematic Draft of the Integrated Meta-Space 
A schematic view of this Integrated Meta-Space is drafted in Fig. 5. It illustrates the combination of the Production Map and the Innovation Map. Ideas that are generated within the Value Production Space are injected into the Business Innovation Space, where they start the innovation process. Following the innovation process, these ideas circulate between the creative units of the BIS. After their elaboration, these and other external ideas or innovations are injected into the VPS and applied to the value production.

In addition to the flow of innovations or ideas, the connection between the production units and the creative units can be modelled. These connections can be highly diverging depending on the modelled level of detail. A creative unit can be either a machine operator generating an idea, while operating a production unit, or a research department which requires a production unit for the creation of a prototype.

\section{Conclusions}

Scientifically the discussion of innovation in combination with the optimisation of production processes is in its infancy. This especially applies for concepts such as VEE. We believe that there are no methodologies which are helping companies to decide whether to invest in optimisation of business processes or going for new innovative products (certainly more risky and costly).

The notion of Virtual Enterprise Environments has been created to enable the combination of open spaces with Virtual Enterprises. The Value Production Space (VPS) is comprised of the internal and external production units and processes for value production connected to the Virtual Enterprise. The Business Innovation Space (BIS) is an open system, comprised of creative units and innovation processes, which allows the integration of external competencies and resources into the networks innovation process.

Initial attempts were made to characterize both spaces and to map their internal processes. In addition to their direct connections (e.g. between human resources and manufacturing tools) the flow of ideas and innovations can be mapped. Ideas generated within the VPS can be elaborated within the BIS and re-injected into the VPS to generate innovations.

Further research is needed regarding the elaboration of their structure and the connection of their elements. This shall led in the development or application of a modelling language. This research will continue during the progress of the BIVEE project.

\section{References}

1. Eschenbecher, J.: Gestaltung von Innovationsprozessen. Mainz GmbH, Aachen (2009)

2. Chesbrough, H.: Managing Open Innovation. Research \& Technology Management 47(1), 23-26 (2004)

3. Eschenbaecher, J., Graser, F.: Managing and Optimizing Innovation Processes in Collaborative and Value creating Networks. International Journal of Innovation and Technology Management 8(3), 373-391 (2009) 
4. Borchert, J.-E.: Operatives Innovationsmanagement in Unternehmensnetzwerken: Gestaltung von Instrumenten für Innovationsprojekte. Cuvillier, Göttingen (2006)

5. O'Sullivan, D., Cormican, K.: A Collaborative Knowledge Management Tool for Product Innovation Management. International Journal of Technology Management 26(1), 53-67 (2003)

6. Giachetti, C., Marchi, G.: Evolution of firms' product strategy over the life cycle of technology-based industries: A case study of the global mobile phone industry, 19802009. Business History 52(7), 1123-1150 (2010)

7. Funk, J.L.: The Product Life Cycle Theory and Product Line Management: The Case of Mobile Phones. IEEE Transactions on Engineering Management 51(2), 142-152 (2004)

8. Abernathy, W., Clark, K.: Innovation: Mapping the winds of creative destruction. Res. Pol. 14, 3-22 (1985)

9. Ulrich, K., Eppinger, S.: Product Design and Development. McGraw-Hill, New York (1995)

10. Camarinha-Matos, L.M., Afsarmanesh, H.: A comprehensive modelling framework for collaborative networked organizations. Journal of Intelligent Manufacturing 18, 529-542 (2007)

11. Cheng, J.: iPhone in depth: The Ars review, http://arstechnica.com/apple/reviews/2007/07/ iphone-review.ars / 6

12. STL Partners Ltd.: Apple vs. Nokia: strategic lessons from the Smartphone / Appstore Wars,

http: / /www.telco2research.com/articles /

AN_Apple-vs-Nokia-smartphone-appstore-wars_Summary

13. Strategy Analytics: Q1 2010 Global Smartphone Market Share Update report, http: / /www.strategyanalytics.com

14. Strategy Analytics: Global Smartphone Vendor Market Share: Q2 2011, http://www.strategyanalytics.com

15. West, J., Mace, M.: Browsing as the killer app: Explaining the rapid success of Apple's iPhone. Telecommunications Policy 34, 270-286 (2010)

16. Chesbrough, H.: Open Innovation: The new Imperative for Creating and Profiting from Technology. Boston Harvard Business School Press, Boston (2003)

17. Chesbrough, H.: Open Business Models: How to Thrive in the New Innovation Landscape. Harvard Business School Press, Boston (2006)

18. Rai, A., Sambamurthy, V.: Editorial Notes - The Growth of Interest in Service Management: Opportunites for Information Systems Scholars. Information Systems Research 17(4), 327-331 (2006)

19. Schierenbeck, H.: Grundzüge der Betriebswirtschaftslehre, 12th edn., Munich, pp. 49-52 (1995)

20. Schumpeter, J.A.: The theory of economic development: An Inquiry into Profits, Capital, Credit, Interest, and the Business Cycle. Transaction Publishers, USA (1931) 